\title{
Increasing obesity and comorbidity in patients undergoing primary total hip arthroplasty in the U.S.: A 13-year study of time trends
}

Jasvinder A Singh ${ }^{1,2,3^{*}}$ and David G Lewallen ${ }^{3}$

\begin{abstract}
Background: Few, if any data are available are available regarding the time-trends in characteristics of patients who have undergone primary THA. Our objective was to examine the time-trends in key demographic and clinical characteristics of patients undergoing primary total hip arthroplasty (THA).

Methods: We used the data from the Mayo Clinic Total Joint Registry from 1993-2005 to examine the time-trends in demographics (age, body mass index (BMI)), medical (Deyo-Charlson index) and psychological comorbidity (anxiety, depression) and underlying diagnosis of patients undergoing primary THA. Chi-square test and analysis for variance were used. Multivariable-adjusted logistic regression (age, sex, comorbidity-adjusted) compared 1993-95 to other study periods. Odds ratio (OR) and 95\% confidence interval (Cl) are presented.

Results: The primary THA cohort consisted of 6,168 patients with 52\% women. In unadjusted analyses, compared to 1993-95, significantly more patients (by >2-times for most) in 2002-05 had: BMI $\geq 40,2.3 \%$ vs. 6.3\%; depression, 4.1\% vs. 9.8\%; and anxiety, 3.4\% vs. 5.7\%; and significantly fewer had an underlying diagnosis of rheumatoid/inflammatory arthritis, $3.7 \%$ vs. $1.5 \%$ ( $p \leq 0.01$ for all). In multivariable-adjusted models, compared to 1993-95, significantly more patients in 2003-05 had (all p-values $\leq$ 0.01): BMI $\geq 40, \mathrm{OR}, 2.79$ (95\% Cl: 1.85, 4.22); Deyo-Charlson Index $\geq 3,1.32$ (1.07, 1.63); depression, $2.25(1.66,3.05)$; and anxiety, $1.71(1.19,2.15)$. Respectively, fewer patients had a diagnosis of RA/inflammatory arthritis: $0.28(0.17,0.46 ; p<0.01)$. Over the 13-year study period, Deyo-Charlson index increased by $22 \%(0.9$ to 1.1$)$ and the mean age decreased by 0.7 years (65.0 to 64.3) ( $p<0.01$ for both).

Conclusions: Obesity, medical and psychological comorbidity increased and the underlying diagnosis of RA/inflammatory arthritis decreased rapidly in primary THA patients over 13-years. Our cohort characteristics are similar to previously described characteristics of national U.S. cohort, suggesting that these trends may be national rather than local trends. This is important information for policy makers to take into account for resource allocation. Studies of THA outcomes and utilization should take these rapidly changing patient characteristics into account.
\end{abstract}

Keywords: Total hip replacement, Time trends, Arthroplasty, Joint replacement, Diagnosis, Obesity, Comorbidity, Osteoarthritis

\footnotetext{
* Correspondence: Jasvinder.md@gmail.com

${ }^{1}$ Medicine Service, Birmingham VA Medical Center, Birmingham, AL, USA

${ }^{2}$ Department of Medicine at School of Medicine, and Division of

Epidemiology at School of Public Health, University of Alabama, Faculty

Office Tower 805B, 510 20th Street S, Birmingham, AL 35294, USA

Full list of author information is available at the end of the article
} 


\section{Background}

Total hip arthroplasty (THA) has been called the operation of the century [1]. Primary THA is the second most common joint replacement surgery performed in the U.S. [2], associated with a significant improvement in patient outcomes [3]. The utilization of primary THA is rapidly increasing and 478,000 primary THA procedures were performed in the U.S. in 2009 [4,5]. Recent studies have described the time-trends in THA utilization [6-10], outcomes [6,8-11] and select patient characteristics (age, obesity) $[6,9,10]$. On the other hand, time-trends in important characteristics of patients undergoing THA, including body mass index (BMI), medical/ psychological comorbidity etc. associated with THA outcomes, have not been examined. Most studies were done in non-U.S. settings $[8,11]$, except three key studies using data from the Medicare [6], the National Inpatient sample (NIS) [9] and the National Hospital Discharge Survey (NHDS) [10]. Several knowledge gaps exist in this area, as summarized in the following section.

In Medicare recipients 65 years and older, the number of comorbidities increased from 1.0 to 2.0 and obesity rates increased from $2.2 \%$ to $7.6 \%$ from 1991 to 2008 [6]. Representative studies of the U.S. NIS from 1998 to 2008 and U.S. NHDS data 1990 to 2004, that included all age groups, showed that among patients undergoing THA, age decreased by 2.1 years [9], Deyo comorbidity index increased from 0.48 to 0.65 [9] and obesity increased from 2.2\% to 3.8\% [10]. Data from these Medicare, NIS and NHDS studies are limited in several important aspects: (1) obesity, linked to THA outcomes [12-15], was captured with a diagnostic code, which is associated with significant under-coding compared to when using the weight and height data [16], as evident in low obesity rates $<5 \%$ in these studies vs. U.S. obesity rates of $37 \%$ in 2009 , proving that the use of ICD-9 code for obesity leads to high misclassification rate [17]; and (2) anxiety, depression and underlying diagnosis, important predictors of THA outcomes [14,18-22], were not assessed. Data from Medicare study are additionally limited in that they are not representative, since at least $1 / 3 \mathrm{rd}$ of all THAs are performed in those younger than 65 years $[23,24]$, the fastest growing age group for the receipt of THA over time [25]. A recent study in TKA cohort found that rates of extreme obesity, Deyo-Charlson index score $>=3$, depression and anxiety increased 2-3 fold from 1993-2005 [26]. To our knowledge, there is lack of such data for time-trends in BMI, anxiety, depression and underlying diagnoses in patients undergoing THA in the U.S.

One of the most remarkable changes in the epidemiology of primary THA in the last two decades is the expanding indication of THA to both younger and older patients. Studies have not examined whether the time-trends in important clinical characteristics (BMI, underlying diagnosis and medical and psychiatric comorbidity) vary by age, the most rapidly changing characteristic of patients undergoing primary THA. Knowing how the patient complexity has changed over time is critically important, since these patient characteristics can have a significant impact on THA outcomes. Our objectives were to: (1) examine the time trends in BMI, underlying diagnosis and medical and psychiatric comorbidity in patients undergoing primary THA; and (2) assess whether these time-trends are different in various patient age groups.

\section{Methods}

We report the methods and results as recommended in the Strengthening of Reporting in Observational studies in Epidemiology (STROBE) statement [27].

\section{Study cohort selection}

The Mayo Clinic Total Joint Registry, a large institutional registry that has prospectively collected preoperative and postoperative follow-up data on all THA patients at the Mayo Clinic, Rochester, served as the data source for this study [28]. Preoperative data, the focus of this study, are collected at the in-clinic visit by the orthopedic surgeons using a standardized data collection form. Since 1993, trained, dedicated Total Joint Registry staff has captured and entered these data into electronic database and ensured the completeness of data. The Mayo Clinic's Institutional Review Board approved the research study. All investigations were conducted in conformity with ethical principles of research.

\section{Study outcomes}

The study period was divided into roughly equal four intervals (1993-95, 1996-98, 1999-2001 and 2002-05). The study outcomes of interest were patient's demographic and clinical characteristics and medical and psychological comorbidity. Patient characteristics and clinical variables were categorized as follows. BMI was categorized as $<25$, overweight, 25-29.9, obese and very obese (obesity class I and II), 30-39.9, or extremely obese (obesity class III), $\geq 40$ as previously [14,29,30], as per WHO classification [31]. Age was categorized as $<50,50-<65,65-<80, \geq 80$, to allow comparison to other studies using Medicare data that only include patients 65 years and older. The operative diagnosis was categorized as osteoarthritis, rheumatoid arthritis (RA)/inflammatory arthritis and other.

Medical comorbidity was assessed with the DeyoCharlson index [32], a validated measure of comorbidity. It is a summative weighted score based on the presence of 17 comorbidities (including cardiac, pulmonary, renal, hepatic disease, diabetes, cancer, hemiplegia etc.) $[33,34]$, captured based on the presence of International Classification of Diseases, ninth revision, common 
modification (ICD-9-CM) diagnostic codes. Deyo-Charlson index was categorized as none, one, two and three or more, similar to previous studies [35], and comorbidities were also assessed individually. Depression and anxiety were assessed based on the presence of ICD-9-CM diagnostic codes.

\section{Statistical analyses}

We calculated summary statistics as proportion or mean (standard deviation). We used chi-square tests to compare the proportions of patients with each category of patient characteristic (BMI, underlying diagnosis, Deyo-Charlson index, depression and anxiety) over time, and also also comparisons of categorical variables in 1993-95 vs. 2005-08. We used the analysis of variance to compare means (age, BMI, Deyo-Charlson index) in various time periods.

We also examined the time trends in the proportion of patients with extreme obesity (BMI $\geq 40$; obesity class III) and high comorbidity (Deyo-Charlson index $\geq 3$ ) using logistic regression. We examined the time trends in $\mathrm{BMI} \geq 40$, RA/inflammatory arthritis as underlying diagnosis, Deyo-Charlson index of $\geq 3$, depression and anxiety, within each age group, using multivariable-adjusted logistic regression analyses. Time-period was considered in four category nominal variable (1993-1995, reference category), and the BMI $<40$, other diagnoses, Deyo-Charlson index of $\leq 2$ and absence of depression or anxiety serving as the reference category for each respective outcome. The overall $\mathrm{p}$-value for the variable was considered as an indicator of whether there was a period effect; visual inspection of the odds ratios was interpreted for timetrend. We performed statistical analyses using Statistical Package for Social Sciences (SPSS, version 21, Chicago, IL). A p-value $<0.05$ was considered significant.

\section{Results}

The primary THA cohort consisted or 6,168 patients, $52 \%$ were women, $10 \%$ were 80 years or older, $5 \%$ had BMI of 40 or more, $38 \%$ had ASA grade III-IV, the underlying diagnosis was OA in $87 \%$ and $64 \%$ had cemented/hybrid implant fixation (Table 1).

\section{Time trends in socio-demographic and clinical characteristics and comorbidity}

The mean age decreased by 0.7 years and mean BMI increased by $1.6 \mathrm{~kg} / \mathrm{m}^{2}$ over the 13 -year period of study, both statistically significant. The prevalence of BMI $\geq 30$ (obesity class I-III) and $\geq 40$ (obesity class III) increased from $33.2 \%$ to $37.1 \%$ and $2.3 \%$ to $6.3 \%$ during the study period, respectively. The proportion of younger patients ( $\leq 50$ years) increased from $13.7 \%$ to $16 \%$ and the prevalence of RA/inflammatory arthritis as the underlying diagnosis decreased from $3.7 \%$ in $1993-95$ to $1.3 \%$ in 2002-05 (Table 2). The proportion of primary THA
Table 1 Preoperative patient characteristics of the primary THA cohort

\begin{tabular}{|c|c|}
\hline & $\begin{array}{l}\text { Primary THA }(n=6,168) N(\%) \\
\text { or Mean (SD) }\end{array}$ \\
\hline \multicolumn{2}{|l|}{ Gender } \\
\hline Females & $3175(52 \%)$ \\
\hline Males & $2993(48 \%)$ \\
\hline \multicolumn{2}{|l|}{ Age } \\
\hline$<50$ & $975(16 \%)$ \\
\hline $50-<65$ & $1626(26 \%)$ \\
\hline $65-<80$ & 2947 (48\%) \\
\hline$\geq 80$ & $620(10 \%)$ \\
\hline \multicolumn{2}{|l|}{ Body Mass Index (BMI) } \\
\hline$<25$ & 1505 (24\%) \\
\hline $25-29.99$ & $2356(38 \%)$ \\
\hline $30-34.99$ & $1497(24 \%)$ \\
\hline $35-39.99$ & $506(8 \%)$ \\
\hline$\geq 40$ & $279(5 \%)$ \\
\hline \multicolumn{2}{|c|}{ American Society of Anesthesiologists (ASA) class } \\
\hline I & $359(6 \%)$ \\
\hline$\|$ & $3468(56 \%)$ \\
\hline III & $2256(37 \%)$ \\
\hline IV & $59(1 \%)$ \\
\hline \multicolumn{2}{|l|}{ Underlying Diagnosis } \\
\hline Inflammatory arthritis & $162(2 \%)$ \\
\hline Osteoarthritis & 5339 (87\%) \\
\hline Other & $666(11 \%)$ \\
\hline \multicolumn{2}{|l|}{ Cement Fixation } \\
\hline Uncemented & $2224(36 \%)$ \\
\hline Cemented/hybrid & 3943 (64\%) \\
\hline Age, mean (SD) & $64.2(13.8)$ \\
\hline Deyo-Charlson Index, mean (SD) & $1.0(1.9)$ \\
\hline BMI, mean (SD) & $28.9(5.8)$ \\
\hline
\end{tabular}

Missing data: $B M I, n=25$; ASA score, $n=26$; Underlying diagnosis, $n=1$.

patients with Deyo-Charlson score of 3 or more increased from $12.2 \%$ to $15.1 \%$. The prevalence of psychological comorbidity increased over the study period: depression increased $>2$-fold from $4.5 \%$ to $9.8 \%$ and anxiety from $3.4 \%$ to $5.7 \%$ (Table 2 ).

Compared to 1993-95, significantly more patients (by >2-times for most) in 2002-05 had: BMI $\geq 40$, $2.3 \%$ vs. $6.3 \%$; depression, $4.1 \%$ vs. $9.8 \%$; and anxiety, $3.4 \%$ vs. $5.7 \%$; and significantly fewer had an underlying diagnosis of rheumatoid/inflammatory arthritis, $3.7 \%$ vs. $1.5 \%$ ( $\mathrm{p} \leq 0.01$ for all comparisons using chi-square tests).

The prevalence for several Deyo-Charlson comorbidities increased significantly over the study period and the 
Table 2 Time trends in demographics and clinical characteristics of patients undergoing primary THA, in \%, unless specified otherwise

\begin{tabular}{|c|c|c|c|c|c|}
\hline & 1993-1995 & 1996-1998 & 1999-2001 & 2002-2005 & P-value \\
\hline Age category & & & & & 0.002 \\
\hline$<50$ & 13.7 & 17.1 & 16.2 & 16.0 & \\
\hline $50-<65$ & 24.7 & 25.9 & 26.6 & 27.5 & \\
\hline $65-<80$ & 51.8 & 48.8 & 47.2 & 44.9 & \\
\hline$\geq 80$ & 9.8 & 8.2 & 10.0 & 11.6 & \\
\hline Mean age (SD) & $65.0(13.2)$ & $63.5(14.0)$ & $63.9(14.0)$ & $64.3(13.9)$ & 0.03 \\
\hline Female gender & 51.8 & 50.0 & 52.0 & 51.9 & 0.67 \\
\hline BMI & & & & & $<0.001$ \\
\hline$<25$ & 28.1 & 26.0 & 24.0 & 21.5 & \\
\hline $25-29.9$ & 38.8 & 40.0 & 37.9 & 37.2 & \\
\hline $30-34.9$ & 23.5 & 24.1 & 23.6 & 25.8 & \\
\hline $35-39.9$ & 7.3 & 6.6 & 9.1 & 9.3 & \\
\hline$\geq 40$ & 2.3 & 3.3 & 5.3 & 6.3 & \\
\hline Mean BMI (SD) & $28.0(5.2)$ & $28.3(5.2)$ & $29.1(6.0)$ & $29.6(6.2)$ & $<0.001$ \\
\hline Operative Diagnosis & & & & & $<0.001$ \\
\hline Osteoarthritis & 81.8 & 81.0 & 88.2 & 92.2 & \\
\hline RA/inflammatory arthritis & 3.7 & 3.7 & 2.4 & 1.3 & \\
\hline Other & 14.5 & 15.3 & 9.4 & 6.5 & \\
\hline Deyo-Charlson Index & & & & & $<0.001$ \\
\hline 0 & 61.9 & 63.2 & 59.2 & 56.7 & \\
\hline 1 & 17.3 & 17.2 & 15.4 & 16.2 & \\
\hline 2 & 8.7 & 9.3 & 11.0 & 11.9 & \\
\hline 3 or more & 12.2 & 10.2 & 14.4 & 15.1 & \\
\hline Depression & 4.5 & 4.8 & 7.2 & 9.8 & $<0.001$ \\
\hline Anxiety & 3.4 & 3.5 & 4.9 & 5.7 & 0.003 \\
\hline
\end{tabular}

SD, standard deviation; RA, rheumatoid arthritis, BMI, body mass index.

Significant $p$-values are in bold. We used analysis of variance for continuous variables and, chi-squared test for categorical variables.

mean Deyo-Charlson comorbidity index increased by $22 \%$ (Table 3).

\section{Time trends in key patient characteristics within each age} group

We noted a significant increase in prevalence of BMI $\geq 40$ ( $>2$-fold increase each) in two age groups, 50- $<65$ and $65-<80$ (Table 4). Similarly, a significant decline in the underlying diagnosis of RA/inflammatory arthritis was noted in the two age groups, those $<50$ years from $17.9 \%$ to $4.2 \%$ (77\% reduction) and in those $65-<80$ years from $3.5 \%$ to $1.2 \%$ (66\% reduction). The proportion of patients with Deyo-Charlson index of 3 or more increased in $65-<80$ years group, from $16.1 \%$ to $19.9 \%$ (23\% increase; Table 4). The prevalence of depression increased significantly across all four age groups, most impressive in patients younger than 50 years, from $2.9 \%$ to $8.3 \%$ (almost 3 -fold). The prevalence of anxiety increased in all age groups, but was not statistically significant, except for a trend in 80 and older age group, from $3.4 \%$ to $5.7 \%$ $(\mathrm{p}=0.06$; Table 4).

\section{Unadjusted and adjusted odds in key patient characteristics over time}

In the unadjusted analyses, compared to 1993-95, the odds of $\mathrm{BMI} \geq 40$ in the next three time periods were 1.46, 2.43 and 2.90 (Table 5). These odds attenuated minimally after adjusting for age-, sex- and comorbidity in the multivariable-adjusted models (Table 5). Compared to 1993-95, the unadjusted odds of RA/inflammatory arthritis as the underlying diagnosis were 1.00, 0.59 and 0.31 in the three next time periods (Table 5). The respective unadjusted odds for medical and psychological comorbidity were as follows: (1) for Deyo-Charlson index of 3 or more, 0.82, 1.21 and 1.28; (2) depression, 1.07, 1.64 and 2.30; and (3) anxiety, 1.04, 1.48 and 1.74, respectively (Table 5). The higher odds for Deyo-Charlson, depression and anxiety also were minimally attenuated with 
Table 3 Time trends in prevalence of medical comorbidity (in \%) from 1993 to 2005 in patients undergoing primary THA

\begin{tabular}{|c|c|c|c|c|c|}
\hline & 1993-1995 & 1996-1998 & 1999-2001 & 2002-2005 & P-value \\
\hline \multicolumn{6}{|l|}{ Deyo-Charlson comorbidities } \\
\hline Myocardial Infarction & 4.0 & 4.2 & 4.1 & 4.7 & 0.76 \\
\hline Congestive Heart Failure & 2.5 & 2.8 & 3.5 & 4.1 & 0.05 \\
\hline Peripheral Vascular Disease & 4.7 & 3.8 & 4.2 & 5.6 & 0.07 \\
\hline Cerebrovascular disease & 5.5 & 5.2 & 6.3 & 7.9 & 0.006 \\
\hline Dementia & 0 & 0 & 0.3 & 0.4 & 0.02 \\
\hline COPD & 9.7 & 8.8 & 10.2 & 9.7 & 0.66 \\
\hline Peptic ulcer disease & 5.5 & 6.3 & 6.2 & 6.3 & 0.81 \\
\hline Mild liver disease & 1.4 & 0.6 & 1.1 & 1.2 & 0.20 \\
\hline Diabetes & 4.8 & 5.0 & 5.9 & 8.0 & $<0.001$ \\
\hline Diabetes with end organ damage & 0.9 & 0.7 & 1.8 & 2.0 & 0.005 \\
\hline Hemiplegia & 0.3 & 0.2 & 0.2 & 0.5 & 0.48 \\
\hline Moderate/severe renal disease & 2.6 & 3.2 & 5.4 & 5.9 & $<0.001$ \\
\hline Moderate/severe liver disease & 0.5 & 0.3 & 0.2 & 0.3 & 0.58 \\
\hline Metastatic solid tumor & 3.3 & 2.3 & 3.6 & 2.7 & 0.12 \\
\hline AIDS & 0 & 0.1 & 0 & 0 & 0.32 \\
\hline Rheumatologic disease & 6.1 & 5.2 & 5.4 & 5.2 & 0.67 \\
\hline Other cancer & 11.2 & 10.9 & 13.5 & 13.9 & 0.02 \\
\hline Mean Deyo-Charlson score (SD) & $0.9(1.8)$ & $0.9(1.7)$ & $1.1(2.0)$ & $1.1(2.0)$ & $<0.001$ \\
\hline
\end{tabular}

COPD, Chronic Obstructive Pulmonary Disease; AIDS, Acquired Immune Deficiency Disease; SD, standard deviation.

Significant $\mathrm{p}$-values are in bold, calculated with chi-squared test.

the adjustment for age, sex- and comorbidity in the multivariable-adjusted models (Table 5).

\section{Discussion}

In this study in patients undergoing primary THA, we found increasing rates of obesity, medical and psychological comorbidity and a decreasing rate of RA/inflammatory arthritis as the underlying diagnosis over time. To our knowledge, this is the first study to comprehensively examine time-trends in depression, anxiety, medical comorbidities and underlying diagnosis, overall and in different age groups of patients undergoing primary THA. The younger age group is the fastest growing group for the receipt of THA over time among all age groups $[23,25]$. Several study findings deserve further discussion.

A key finding from our study was that the prevalence of obesity, including extreme obesity (BMI $\geq 40$ ), differed significantly by time and seemed to increase over time. By using the height and weight data prospectively captured in the joint registry, we were able to get accurate estimates of obesity and overcame a key limitation of under-diagnosis of obesity based on the use of ICD-9-CM diagnostic code [16] in all the previous studies [6,10]. Among the patients undergoing primary THA, obesity increased from 33.2\% in 1992-95 to 37.1\% for in 2002-05. In the U.S. Medicare population, the prevalence of obesity was reported to increase from $2.2 \%$ in 1991 to $7.6 \%$ in 2008 [6] and in the NIS from $2.2 \%$ in 1990 to $5.0 \%$ in 2004 [10]. Thus, our study is the first to examine the change in BMI over time in a U.S. cohort undergoing THA. The prevalence of obesity of $37 \%$ in our 2002-2005 cohort was higher than the $24.5 \%$ reported in 2004 for the general U.S. population [17]. Comparing the prevalence of obesity of $5 \%$ in the NIS study using the ICD-9 code to the $37 \%$ using height and weight data in our study, highlights the extent of under-coding of obesity using ICD-9-CM codes in administrative databases (by 7 -fold relative and $32 \%$ absolute difference) and the resulting misclassification in earlier studies. Our cohort's demographic and clinical characteristics are similar to those reported from the U.S. NIS, indicating that our sample is representative. This should be comforting to clinicians who might be worried that our institution does not have a representative population, since the Mayo Clinic provides THA to local residents and is also a referral center. To our knowledge, no systematic changes occurred in referral patterns from primary care physicians to orthopedic surgery or policy for reimbursement for primary THA (except slight uniform reduction in compensation across the health care system) in the U.S. during the study period that would explain the time-trends in these characteristics. Another contribution from our study to the literature was our ability to provide overall and age-specific time-trends in BMI and to examine time-trends in extreme obesity. 
Table 4 Time-trends in patient characteristics (in \%) by patient age category from 1993 to 2005 in patients undergoing primary THA

\begin{tabular}{|c|c|c|c|c|c|}
\hline & 1993-1995 & 1996-1998 & 1999-2001 & 2002-2005 & P-value \\
\hline \multicolumn{6}{|l|}{$\mathrm{BMI} \geq 40$} \\
\hline Age, $<50$ & 1.1 & 7.3 & 7.2 & 5.8 & 0.30 \\
\hline Age, $50-<65$ & 3.5 & 5.3 & 7.1 & 9.3 & 0.007 \\
\hline Age, $65-<80$ & 2.4 & 1.3 & 4.6 & 5.7 & $<0.001$ \\
\hline Age $\geq 80$ & 0 & 0 & 1.3 & 2.2 & 0.17 \\
\hline \multicolumn{6}{|c|}{ Diagnosis of RA/inflammatory arthritis } \\
\hline Age, $<50$ & 17.9 & 10.5 & 6.2 & 4.2 & $<0.001$ \\
\hline Age, $50-<65$ & 2.6 & 3.3 & 1.9 & 1.0 & 0.11 \\
\hline Age, 65- <80 & 3.5 & 4.2 & 2.3 & 1.2 & 0.002 \\
\hline Age $\geq 80$ & 0 & 0 & 1.4 & 0 & 0.11 \\
\hline \multicolumn{6}{|c|}{ Deyo-Charlson Index $\geq 3$} \\
\hline Age, $<50$ & 5.7 & 1.7 & 4.8 & 4.8 & 0.16 \\
\hline Age, $50-<65$ & 4.1 & 6.7 & 7.8 & 8.2 & 0.13 \\
\hline Age, 65- <80 & 16.1 & 12.7 & 19.8 & 19.9 & $<0.001$ \\
\hline Age $\geq 80$ & 20.8 & 24.1 & 21.9 & 27.2 & 0.51 \\
\hline \multicolumn{6}{|l|}{ Depression } \\
\hline Age, $<50$ & 2.9 & 3.0 & 6.0 & 8.3 & 0.02 \\
\hline Age, $50-<65$ & 5.4 & 4.8 & 8.7 & 9.4 & 0.02 \\
\hline Age, 65- <80 & 4.7 & 5.2 & 6.8 & 9.1 & 0.002 \\
\hline Age $\geq 80$ & 4.0 & 6.3 & 7.1 & 15.8 & 0.001 \\
\hline \multicolumn{6}{|l|}{ Anxiety } \\
\hline Age, $<50$ & 1.7 & 0.9 & 2.4 & 2.9 & 0.41 \\
\hline Age, $50-<65$ & 2.2 & 2.2 & 4.9 & 3.9 & 0.12 \\
\hline Age, 65- <80 & 4.1 & 5.1 & 4.8 & 6.6 & 0.14 \\
\hline Age $\geq 80$ & 3.4 & 3.5 & 4.9 & 5.7 & 0.06 \\
\hline
\end{tabular}

Significant $\mathrm{p}$-values are in bold, calculated with chi-squared test.

An important finding from our study was the doubling of the rates of extreme obesity in $50-<65$ and $65-<80$ age groups and of depression in all 4 age groups. To our knowledge this is the first study to examine these important patient characteristics in various age groups, over time. Examination of these characteristics (extreme obesity, depression etc.) by age groups provides a detailed knowledge of their variation over time by age in primary THA patients. This knowledge can also allow policy makers to direct their efforts towards the group that is most at risk due to rapidly increasing prevalence of these clinical features that are associated with poor prognosis and worse outcomes after primary THA $[12,15,18,19,36]$.

We also found that the prevalence of RA/inflammatory arthritis reduced by $65-75 \%$ in $<50$ and $65-<80$ age groups over the study period. This finding adds to the growing evidence that fewer patients with RA/inflammatory arthritis are requiring THA, compared to $1-2$ decades ago $[5,37,38]$. This may at least partially be due to the availability and more frequent use of effective disease-modifying treatments for RA, including methotrexate and/or biologics [39,40], as recommended in the RA treatment guidelines [41,42].

The time-trends in the prevalence of extreme obesity, depression and anxiety were mostly independent of age, gender and medical comorbidity, as demonstrated in the multivariable-adjusted models. Anxiety and depression are well-recognized predictors of poorer pain and function outcomes after arthroplasty [14,43-45]. This is an important finding, since there were significant time trends of decreasing patient age and increasing medical comorbidity over the same time-period. We noted minimal attenuation of odds ratios comparing unadjusted to multivariableadjusted models, implying that increasing obesity, depression and anxiety in primary THA patients is not the result of increasing medical comorbidity or decreasing age.

In our study, we found rapidly increasing prevalence of moderate to severe renal disease, cerebrovascular disease and dementia over time. To our knowledge, this has not been reported previously in primary THA patients. This finding indicates that surgeons and patients need to 
Table 5 Unadjusted and adjusted odds of extreme obesity (BMI of $\mathbf{4 0}$ or higher), an underlying operative diagnosis of RA/inflammatory arthritis, Deyo-Charlson index of 3 or higher, depression or anxiety over time

\begin{tabular}{|c|c|c|c|c|}
\hline & 1993-1995 & 1996-1998 & 1999-2001 & 2002-2005 \\
\hline \multicolumn{5}{|l|}{$\mathrm{BMI} \geq \mathbf{4 0}$} \\
\hline Unadjusted & Ref & $1.46(0.91,2.35)$ & $2.43(1.58,3.73)^{*}$ & $2.90(1.92,4.37)^{*}$ \\
\hline Age- and sex-adjusted & Ref & $1.41(0.85,2.26)$ & $2.36(1.53,3.63)^{*}$ & $2.84(1.88,4.29)^{*}$ \\
\hline Comorbidity-adjusted & Ref & $1.47(0.92,2.37)$ & $2.40\left(1.56,3.69^{*}\right.$ & $2.87(1.90,4.33)^{*}$ \\
\hline Age-, sex- and comorbidity adjusted & Ref & $1.42(0.88,2.28)$ & $2.30(1.50,3.55)^{*}$ & $2.79(1.85,4.22)^{*}$ \\
\hline \multicolumn{5}{|l|}{ Diagnosis of RA/inflammatory arthritis ${ }^{\mathrm{a}}$} \\
\hline Unadjusted & Ref & $1.00(0.67,1.50)$ & $0.59(0.38,0.91)^{9}$ & $0.31(0.19,0.51)^{*}$ \\
\hline Age- and sex-adjusted & Ref & $0.97(0.65,1.46)$ & $0.55(0.35,0.85)^{\dagger}$ & $0.29(0.18,0.48)^{*}$ \\
\hline Comorbidity-adjusted & Ref & $1.00(0.67,1.51)$ & $0.58(0.38,0.90)^{\pi}$ & $0.31(0.19,0.50)^{*}$ \\
\hline Age-, sex- and comorbidity adjusted & Ref & $0.99(0.66,1.48)$ & $0.53(0.34,0.83)^{\dagger}$ & $0.28(0.17,0.46)^{*}$ \\
\hline \multicolumn{5}{|l|}{ Deyo-Charlson Index $\geq 3^{b}$} \\
\hline Unadjusted & Ref & $0.82(0.64,1.04)$ & $1.21(0.97,1.51)$ & $1.28(1.04,1.58)^{n}$ \\
\hline Age- and sex-adjusted & Ref & $0.86(0.67,1.10)$ & $1.26(1.01,1.58)^{n}$ & $1.32(1.07,1.63)^{\dagger}$ \\
\hline \multicolumn{5}{|l|}{ Depression } \\
\hline Unadjusted & Ref & $1.07(0.74,1.53)$ & $1.64(1.18,2.27)^{\dagger}$ & $2.30(1.70,3.11)^{*}$ \\
\hline Age- and sex-adjusted & Ref & $1.09(0.76,1.56)$ & $1.65(1.19,2.29)^{\dagger}$ & $2.31(1.71,3.13)^{*}$ \\
\hline Comorbidity-adjusted & Ref & $1.09(0.76,1.56)$ & $1.59(1.15,2.21)^{\dagger}$ & $2.24(1.66,3.04)^{*}$ \\
\hline Age-, sex- and comorbidity adjusted & Ref & $1.11(0.77,1.59)$ & $1.60(1.15,2.22)^{\dagger}$ & $2.25(1.66,3.05)^{*}$ \\
\hline \multicolumn{5}{|l|}{ Anxiety } \\
\hline Unadjusted & Ref & $1.04(0.69,1.59)$ & $1.48(1.01,2.17)^{9}$ & $1.74(1.22,2.49)^{\dagger}$ \\
\hline Age- and sex-adjusted & Ref & $1.09(0.72,1.66)$ & $1.51(1.03,2.21)^{\pi}$ & $1.75(1.22,2.51)^{\dagger}$ \\
\hline Comorbidity-adjusted & Ref & $1.07(0.70,1.62)$ & $1.44(0.98,2.11)$ & $1.70(1.18,2.43)^{\dagger}$ \\
\hline Age-, sex- and comorbidity adjusted & Ref & $1.10(0.73,1.68)$ & $1.47(1.00,2.15)$ & $1.71(1.19,2.15)^{\dagger}$ \\
\hline
\end{tabular}

Ref, reference category, has an odds ratio of 1.0 .

${ }^{a}$ Osteoarthritis is the reference category for diagnosis.

${ }^{\mathrm{b}}$ Since the variable under study was Deyo-Charlson index, comorbidity-adjusted models were not run.

"P $<0.05 ;{ }^{\dagger} P \leq 0.01 ; * P \leq 0.001$.

Significant odds ratios are in bold.

be aware of increasing rate of certain comorbidities over time, which may be associated with an increase in peri-operative complications. This needs further study.

Our study confirms several previous findings including a reduction in mean age and increase in Deyo-Charlson index for patients undergoing primary THA. Findings from the study of the U.S. NIS showed that Deyo-Charlson index increased 0.42 to 0.55 (30\% increase) from 1998-2008 in patients undergoing THA [9], similar to the $36 \%$ increase noted in our study. The magnitude of increases is lower compared to a $100 \%$ increase of comorbidity from 1 to 2 in Medicare sample from 1991 to 2008 [6]. This is not surprising due to the inclusion of all-comers in our and the NIS study vs. only patients 65 years and older (with higher comorbidity) in the Medicare sample. Our study also confirms a doubling of the prevalence of diabetes in patients undergoing primary THA over last 10-15 years, as reported in analyses of Medicare $(7.1 \%$ in $1991-92$ to $15.5 \%$ in
2007-08) [6] and the NIS data $(6.8 \%$ in 1990-94 to $11 \%$ in 2000-04) [10].

Our study showed that the change in primary THA patient characteristics with increasing obesity and medical and psychological comorbidity is evident. These timetrends need to be accounted in research studies of THA outcomes and when health care plans and policy makers are making the reimbursement and coverage decisions. Data on several important patient characteristics are limited or absent in Medicare and NIS datasets that can be examined more comprehensively using data from total joint registries, similar to ours.

Our study has several limitations that should be taken into account while interpreting study findings. Our cohort study is subject to residual confounding due to study design, despite the adjustment for several important covariates in our multivariable-adjusted analyses. We used ICD-9 diagnostic codes to define anxiety and depression, and therefore these are likely under-reported. In addition, 
the increasing incidence of anxiety and depression over time might indicate either a better capture/reporting of these or a true increase in its incidence in this patient population. We are unable to distinguish between these two possibilities.

Study strengths include the use of height/weight data for BMI, a representative sample from a well-established U.S. total joint registry, availability of electronically captured data for more than a decade and robustness of our findings across several sensitivity models (age-adjusted vs. age- and sex-adjusted vs. age, sex- and comorbidity-adjusted models). The similarity of our cohort to other published studies of THA $[8,12,13,46]$ as well as the NIS sample $[9,47]$, supports the generalizability of these findings.

\section{Conclusion}

In conclusion, we observed an increasing prevalence of obesity, medical and psychological comorbidity and decreasing prevalence of RA/inflammatory arthritis over a 13-year study period in patients undergoing primary THA. The time-trends differed by the age category. These timetrends in patient characteristics should be accounted for when comparing results over time and performing studies that include several years of data. Our study findings should be resource for public policy makers and those comparing resource use across interventions and procedures and making reimbursement decisions. These data represent the changing complexity of primary THA patients in the U.S., which can potentially impact outcomes.

\section{Competing interests}

There are no financial conflicts related directly to this study. J.A.S. has received research and travel grants from Takeda and Savient; and consultant fees from Savient, Takeda, Regeneron, and Allergan. J.A.S. is a member of the executive of OMERACT, an organization that develops outcome measures in rheumatology and receives arms-length funding from 36 companies; a member of the American College of Rheumatology's Guidelines Subcommittee of the Quality of Care Committee; and a member of the Veterans Affairs Rheumatology Field Advisory Committee. D.G.L. has received royalties/speaker fees from Zimmer, Orthosonic and Osteotech, has been a paid consultant and owns stock in Pipeline Biomedical and his institution has received research funds from DePuy, Stryker, Biomet and Zimmer.

\section{Authors' contributions}

JAS was responsible for study conception and design, development of study protocol methods and analyses, review of statistical analyses, preparing the first draft of the manuscript, critical revisions, approval of the final manuscript version and the submission of the manuscript. DGL reviewed the study design and study protocol and provided comments, reviewed statistical analyses, and provided critical revisions for the manuscript and the approval of the final manuscript version.

\section{Grant support}

This material is the result of work supported Mayo Clinic Orthopedic Surgery research funds and the resources and use of facilities at the Birmingham VA Medical Center, Alabama, USA. J.A.S. is also supported by grants from the Agency for Health Quality and Research Center for Education and Research on Therapeutics (AHRQ CERTs) U19 HS021110, National Institute of Arthritis, Musculoskeletal and Skin Diseases (NIAMS) P50 AR060772 and U34 AR062891, National Institute of Aging (NIA) U01 AG018947, and National Cancer Institute (NCI) U10 CA149950, and research contract CE-1304-6631 from the Patient Centered Outcomes Research Institute (PCORI).

\section{IRB approval}

The Mayo Clinic Institutional Review Board approved this study and all investigations were conducted in conformity with ethical principles of research.

\section{Author details}

${ }^{1}$ Medicine Service, Birmingham VA Medical Center, Birmingham, AL, USA. ${ }^{2}$ Department of Medicine at School of Medicine, and Division of Epidemiology at School of Public Health, University of Alabama, Faculty Office Tower 805B, 510 20th Street S, Birmingham, AL 35294, USA. ${ }^{3}$ Department of Orthopedic Surgery, Mayo Clinic College of Medicine, Rochester, MN, USA.

Received: 16 June 2014 Accepted: 10 December 2014

Published: 17 December 2014

\section{References}

1. Learmonth ID, Young C, Rorabeck C: The operation of the century: total hip replacement. Lancet 2007, 370(9597):1508-1519. Epub 2007/10/30

2. HCUP: HCUP Facts and Figures 2009- Section 3: Inpatient Hospital Stays by Procedure. Exhibit 3.1 Most Frequent All-listed Procedures.

http://hcup-us.ahrq.gov/reports/factsandfigures/2009/pdfs/FF_report_2009.pdf.

3. Ethgen O, Bruyere O, Richy F, Dardennes C, Reginster JY: Health-related quality of life in total hip and total knee arthroplasty. A qualitative and systematic review of the literature. J Bone Joint Surg Am 2004, 86-A(5):963-974. Epub 2004/05/01.

4. Healthcare Cost and Utilization Project (HCUP): HCUP Facts and Figures 2009- Section 3: Inpatient Hospital Stays by Procedure. Exhibit 3.1 Most Frequent All-listed Procedures. http://hcup-us.ahrq.gov/reports/ factsandfigures/2009/pdfs/FF_report_2009.pdf. Rockville, MD: Agency for Healthcare Research and Quality; 2012 [updated February 201202/10/2014].

5. Singh JA, Vessely MB, Harmsen WS, Schleck CD, Melton $\amalg$ 3rd, Kurland RL, Berry DJ: A population-based study of trends in the use of total hip and total knee arthroplasty, 1969-2008. Mayo Clin Proc 2010, 85(10):898-904. Epub 2010/09/09.

6. Cram P, Lu X, Kaboli PJ, Vaughan-Sarrazin MS, Cai X, Wolf BR, Li Y: Clinical characteristics and outcomes of Medicare patients undergoing total hip arthroplasty, 1991-2008. JAMA 2011, 305(15):1560-1567. Epub 2011/04/21.

7. Espehaug B, Furnes $\mathrm{O}$, Engesaeter $\mathrm{LB}$, Havelin LI: Hip arthroplasty in Norway 1989-2008. Tidsskr Nor Laegeforen 2011, 131(16):1543-1548.

8. Jimenez-Garcia R, Villanueva-Martinez M, Fernandez-de-Las-Penas C, Hernandez-Barrera V, Rios-Luna A, Garrido PC, de Andres AL, Jimenez-Trujillo I, Montero JS, Gil-de-Miguel A: Trends in primary total hip arthroplasty in Spain from 2001 to 2008: evaluating changes in demographics, comorbidity, incidence rates, length of stay, costs and mortality. BMC Musculoskelet Disord 2011, 12:43. Epub 2011/02/11.

9. Kirksey M, Chiu YL, Ma Y, Della Valle AG, Poultsides L, Gerner P, Memtsoudis SG: Trends in in-hospital major morbidity and mortality after total joint arthroplasty: United States 1998-2008. Anesth Analg 2012, 115(2):321-327.

10. Liu SS, Della Valle AG, Besculides MC, Gaber LK, Memtsoudis SG: Trends in mortality, complications, and demographics for primary hip arthroplasty in the United States. Int Orthop 2009, 33(3):643-651. Epub 2008/05/08.

11. Sheehan E, Neligan M, Murray P: Hip arthroplasty, changing trends in a national tertiary referral centre. Ir J Med Sci 2002, 171(1):13-15. Epub 2002/05/08.

12. Huddleston JI, Wang Y, Uquillas C, Herndon JH, Maloney WJ: Age and obesity are risk factors for adverse events after total hip arthroplasty. Clin Orthop Relat Res 2012, 470(2):490-496. Epub 2011/07/29.

13. Yeung E, Jackson M, Sexton S, Walter W, Zicat B, Walter W: The effect of obesity on the outcome of hip and knee arthroplasty. Int Orthop 2011, 35(6):929-934. Epub 2010/06/01.

14. Singh JA, Lewallen D: Age, gender, obesity, and depression are associated with patient-related pain and function outcome after revision total hip arthroplasty. Clin Rheumatol 2009, 28(12):1419-1430. Epub 2009/09/04.

15. Namba RS, Paxton L, Fithian DC, Stone ML: Obesity and perioperative morbidity in total hip and total knee arthroplasty patients. $J$ Arthroplasty 2005, 20(7 Suppl 3):46-50. Epub 2005/10/11.

16. Ma J, Xiao L, Stafford RS: Underdiagnosis of obesity in adults in US outpatient settings. Arch Intern Med 2009, 169(3):313-314. Epub 2009/02/11.

17. Statistics related to overweight and obesity: Economic Costs Related to Overweight and Obesity, Weight-Control Information Network. Bethesda, MD: 
National Institute of Diabetes and Digestive and Kidney Diseases (NIDDK); 2006. 2013 [03/30/2014].

18. Riediger W, Doering S, Krismer M: Depression and somatisation influence the outcome of total hip replacement. Int Orthop 2010, 34(1):13-18. Epub 2008/11/27.

19. Brull R, McCartney CJ, Chan WW: Do preoperative anxiety and depression affect quality of recovery and length of stay after hip or knee arthroplasty? Can J Anaesth 2002, 49(1):109. Epub 2002/01/10.

20. Judge A, Arden NK, Cooper C, Kassim Javaid M, Carr AJ, Field RE, Dieppe PA: Predictors of outcomes of total knee replacement surgery. Rheumatology (Oxford) 2012, 51(10):1804-1813. Epub 2012/04/26.

21. Baker PN, van der Meulen JH, Lewsey J, Gregg PJ: The role of pain and function in determining patient satisfaction after total knee replacement. Data from the National Joint Registry for England and Wales. J Bone Joint Surg (Br) 2007, 89(7):893-900. Epub 2007/08/04.

22. Pun SY, Ries MD: Effect of gender and preoperative diagnosis on results of revision total knee arthroplasty. Clin Orthop Relat Res 2008, 466(11):2701-2705. Epub 2008/08/30

23. Kurtz SM, Lau E, Ong K, Zhao K, Kelly M, Bozic KJ: Future young patient demand for primary and revision joint replacement: national projections from 2010 to 2030. Clin Orthop Relat Res 2009, 467(10):2606-2612. Epub 2009/04/11.

24. Khatod M, Inacio M, Paxton EW, Bini SA, Namba RS, Burchette RJ, Fithian DC: Knee replacement: epidemiology, outcomes, and trends in Southern California: 17,080 replacements from 1995 through 2004. Acta Orthop 2008, 79(6):812-819. Epub 2008/12/17.

25. Ravi B, Croxford R, Reichmann WM, Losina E, Katz JN, Hawker GA: The changing demographics of total joint arthroplasty recipients in the United States and Ontario from 2001 to 2007. Best Pract Res Clin Rheumatol 2012, 26(5):637-647. Epub 2012/12/12.

26. Singh JA, Lewallen DG: Time trends in the characteristics of patients undergoing primary total knee arthroplasty. Arthritis Care Res (Hoboken) 2014, 66(6):897-906. doi:10.1002/acr.22233. PubMed PMID: 24249702; PubMed Central PMCID: PMC4151514.

27. STROBE Statement: Strengthening the Reporting of Observational Studies in Epidemiology. Bern, Germany: University of Bern; 2007. Link: http://www. strobe-statement.org/fileadmin/Strobe/uploads/checklists/ STROBE checklist v4 cohort.pdf.

28. Berry DJ, Kessler M, Morrey BF: Maintaining a hip registry for 25 years. Mayo Clinic experience. Clin Orthop Relat Res 1997, 344:61-68. Epub 1997/12/31.

29. Singh JA, Gabriel SE, Lewallen DG: Higher body mass index is not associated with worse pain outcomes after primary or revision total knee arthroplasty. J Arthroplasty 2011, 26(3):366-374. e361. Epub 2010/04/ 24. doi:10.1016/j.arth.2010.02.006. PubMed PMID: 20413245; PubMed Central PMCID: PMC2930933.

30. Singh JA, Gabriel S, Lewallen D: The impact of gender, age, and preoperative pain severity on pain after TKA. Clin Orthop Relat Res 2008, 466(11):2717-2723. Epub 2008/08/06.

31. WHO: Obesity; Preventing and Managing the Global Epidemic. Geneva: World Health Organization; 2000.

32. Deyo RA, Cherkin DC, Ciol MA: Adapting a clinical comorbidity index for use with ICD-9-CM administrative databases. J Clin Epidemiol 1992, 45(6):613-619. Epub 1992/06/01.

33. Charlson ME, Pompei $P$, Ales KL, Mackenzie CR: A new method of classifying prognostic comorbidity in longitudinal studies: development and validation. J Chron Dis 1987, 40(5):373-383.

34. Charlson ME, Sax FL, Mackenzie CR, Braham RL, Fields SD, Douglas RG Jr: Morbidity during hospitalization: can we predict it? J Chron Dis 1987, 40(7):705-712.

35. Ehlenbach WJ, Barnato AE, Curtis JR, Kreuter W, Koepsell TD, Deyo RA, Stapleton RD: Epidemiologic study of in-hospital cardiopulmonary resuscitation in the elderly. N Engl J Med 2009, 361(1):22-31. Epub 2009/07/03.

36. Malinzak RA, Ritter MA, Berend ME, Meding JB, Olberding EM, Davis KE: Morbidly obese, diabetic, younger, and unilateral joint arthroplasty patients have elevated total joint arthroplasty infection rates. J Arthroplasty 2009, 24(6 Suppl):84-88.

37. da Silva E, Doran MF, Crowson CS, O'Fallon WM, Matteson EL: Declining use of orthopedic surgery in patients with rheumatoid arthritis? Results of a long-term, population-based assessment. Arthritis Rheum 2003, 49(2):216-220
38. Hekmat K, Jacobsson L, Nilsson JA, Petersson IF, Robertsson O, Garellick G, Turesson C: Decrease in the incidence of total hip arthroplasties in patients with rheumatoid arthritis-results from a well defined population in south Sweden. Arthritis Res Ther 2011, 13(2):R67. 3132062: 3132062.

39. O'Dell JR, Haire CE, Erikson N, Drymalski W, Palmer W, Eckhoff PJ, Garwood V, Maloley P, Klassen LW, Wees S, Klein H, Moore GF: Treatment of rheumatoid arthritis with methotrexate alone, sulfasalazine and hydroxychloroquine, or a combination of all three medications. N Engl J Med 1996, 334(20):1287-1291. Epub 1996/05/16.

40. Gartlehner G, Hansen RA, Jonas BL, Thieda P, Lohr KN: The comparative efficacy and safety of biologics for the treatment of rheumatoid arthritis: a systematic review and metaanalysis. J Rheumatol 2006, 33(12):2398-2408.

41. Singh JA, Furst DE, Bharat A, Curtis JR, Kavanaugh AF, Kremer JM, Moreland LW O'Dell J, Winthrop KL, Beukelman T, Bridges SL Jr, Chatham WW, Paulus HE, Suarez-Almazor M, Bombardier C, Dougados M, Khanna D, King CM, Leong AL, Matteson EL, Schousboe JT, Moynihan E, Kolba KS, Jain A, Volkmann ER, Agrawal H, Bae S, Mudano AS, Patkar NM, Saag KG: 2012 update of the 2008 American college of rheumatology recommendations for the use of disease-modifying antirheumatic drugs and biologic agents in the treatment of rheumatoid arthritis. Arthritis Care Res (Hoboken) 2012, 64(5):625-639. Epub 2012/04/05.

42. Smolen JS, Landewe R, Breedveld FC, Dougados M, Emery P, Gaujoux-Viala C, Gorter S, Knevel R, Nam J, Schoels M, Aletaha D, Buch M, Gossec L, Huizinga T, Bijlsma JW, Burmester G, Combe B, Cutolo M, Gabay C, Gomez-Reino J, Kouloumas M, Kvien TK, Martin-Mola E, McInnes I, Pavelka K, van Riel P, Scholte M, Scott DL, Sokka T, Valesini G, et al: EULAR recommendations for the management of rheumatoid arthritis with synthetic and biological disease-modifying antirheumatic drugs. Ann Rheum Dis 2010, 69(6):964-975. 2935329: 2935329.

43. Lingard EA, Riddle DL: Impact of psychological distress on pain and function following knee arthroplasty. J Bone Joint Surg Am 2007, 89(6):1161-1169.

44. Singh JA, Lewallen DG: Predictors of use of pain medications for persistent knee pain after primary Total Knee Arthroplasty: a cohort study using an institutional joint registry. Arthritis Res Ther 2012, 14(6):R248

45. Singh JA, Lewallen D: Predictors of pain and use of pain medications following primary Total Hip Arthroplasty (THA): 5,707 THAs at 2-years and 3,289 THAs at 5-years. BMC Musculoskelet Disord 2010, 11:90. 2881019: 2881019.

46. Stundner O, Kirksey M, Chiu YL, Mazumdar M, Poultsides L, Gerner P, Memtsoudis SG: Demographics and perioperative outcome in patients with depression and anxiety undergoing total joint arthroplasty: a population-based study. Psychosomatics 2013, 54(2):149-157.

47. Bang H, Chiu YL, Memtsoudis SG, Mandl LA, Della Valle AG, Mushlin Al, Marx RG, Mazumdar M: Total hip and total knee arthroplasties: trends and disparities revisited. Am J Orthop (Belle Mead NJ) 2010, 39(9):E95-E102.

doi:10.1186/1471-2474-15-441

Cite this article as: Singh and Lewallen: Increasing obesity and comorbidity in patients undergoing primary total hip arthroplasty in the U.S.: A 13-year study of time trends. BMC Musculoskeletal Disorders 2014 15:441.

\section{Submit your next manuscript to BioMed Central and take full advantage of:}

- Convenient online submission

- Thorough peer review

- No space constraints or color figure charges

- Immediate publication on acceptance

- Inclusion in PubMed, CAS, Scopus and Google Scholar

- Research which is freely available for redistribution 